\title{
Radioactive Nuclides Diffusion Simulation Analysis of Equipment System Accident
}

\author{
Xin $\operatorname{Ren}^{1,2}$ \\ ${ }^{1}$ Graduate School, National Defense University, Beijing, 100091, China \\ ${ }^{2}$ Naval Medical Research Institute, Shanghai, 200433, China
}

\begin{abstract}
The prediction of the radioactive nuclides concentration of equipment system accident is the basis and premise of equipment system radioprotection and it is an important part of radiation accident emergency rescue. Based on the one-dimensional diffusion model, the radioactive nuclides transient, continuous and steady state pollution spot source model of three-dimensional diffusion of equipment system radioactive nuclides in liquid can be built up, and the quick simulation analysis program of equipment system radioactive nuclides pollution diffusion can be carried out by writing procedure and the diffusion trend of radioactive nuclides can be well imitated. The results of this study can provide scientific basis for making decision and emergency rescue plan.
\end{abstract}

Keywords-equipment system accident; radionuclide diffusion; simulation analysis

\section{INTRODUCTION}

When the radioactive nuclide of equipment system accident is spilled, the dynamic information of radionuclide concentration of equipment system accident needs to be accurately obtained and it can play a key role on the rapid and effective nuclear emergency response. In view of this, the radioactive nuclides transient, continuous and steady state pollution spot source model of three-dimensional diffusion of equipment system radioactive nuclides in liquid will be built up in this paper in order to carry out the real-time dynamic simulation and prediction of radioactive nuclide concentration pollution diffusion of the equipment system accident.

\section{THE ESTABLISHMENT AND SOLUTION OF MATHEMATICAL MODEL}

\section{A. The Establishment of Mathematical Model}

1) Condition Hypothesis and Related Symbols:

(1) $\Omega$ is the water area surrounded by a closed surface $S$ on the river, $\mathrm{C}(\mathrm{x}, \mathrm{y}, \mathrm{z})$ is the radioactive pollutants concentration of location point $(\mathrm{x}, \mathrm{y}, \mathrm{z})$ at time $\mathrm{t}$.

(2) The radioactive pollutants diffuse because of the flow of the river and the molecular free movement, $D_{x}, D_{y}$ and $D_{z}$ are respectively the diffusion coefficient of $\mathrm{x}$ direction, $\mathrm{y}$ direction and $\mathrm{z}$ direction.

(3) $\theta(x, y, z, t)$ is the radioactive pollutant emission of location point $(\mathrm{x}, \mathrm{y}, \mathrm{z})$ in unit time and physical volume at time $\mathrm{t}$.
(4) $u_{x}, u_{y}$ and $u_{z}$ are respectively the water flow velocity along $\mathrm{x}$ direction, $\mathrm{y}$ direction and $\mathrm{z}$ direction, and they are constant in a certain range of time.

2) The Radionuclide Concentration Three-Dimensional Diffusion Model of System Equipment Accident:

The three-dimensional mathematical model of the river pollution is established as follows:

$$
\frac{\partial C}{\partial t}=D_{x} \frac{\partial^{2} C}{\partial x^{2}}+D_{y} \frac{\partial^{2} C}{\partial y^{2}}+D_{z} \frac{\partial^{2} C}{\partial z^{2}}-u_{x} \frac{\partial C}{\partial x}-u_{y} \frac{\partial C}{\partial y}-u_{z} \frac{\partial C}{\partial z}+\theta(x, y, z, t)
$$

The initial conditions: $C(x, y, z, 0)=\lambda(x, y, z)$, the change of equipment system accident radionuclide concentration along with the time after decay can be stated as follows: $\frac{\partial C(x, y, z, t)}{\partial t}=-\frac{0.693}{T} C$. Among the above, $\mathrm{C}$ is the radionuclide concentration of equipment system, $\mathrm{T}$ is the half-life, and $t$ is the elapsed time. The formula (1) can be modified as follows:

$$
\frac{\partial C}{\partial t}=D_{x} \frac{\partial^{2} C}{\partial x^{2}}+D_{y} \frac{\partial^{2} C}{\partial y^{2}}+D_{z} \frac{\partial^{2} C}{\partial z^{2}}-u_{x} \frac{\partial C}{\partial x}-u_{y} \frac{\partial C}{\partial y}-u_{z} \frac{\partial C}{\partial z}+\theta(x, y, z, t)-\frac{0.693}{T} C
$$

\section{B. The Solution of Mathematical Model}

Fourier transformation of the four-dimensional model of water quality on both sides can be carried out at the same time:

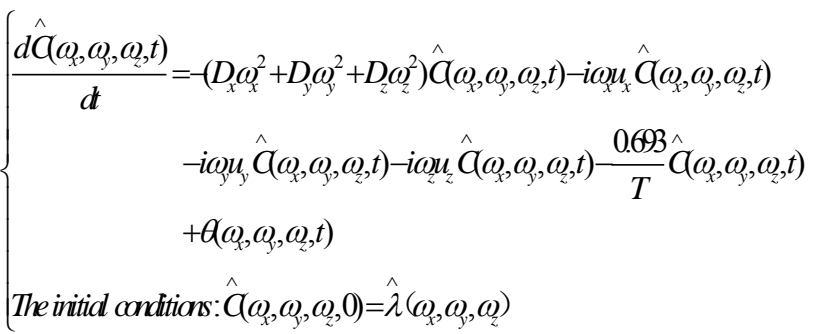

1) The radionuclide concentration instantaneous pollution point source three-dimensional diffusion model of equipment system accident: 
In the three-dimensional flow water, the equipment system accident radioactive nuclide concentration pollution source is instantaneously launched in coordinate $\left(x_{0}, y_{0}, z_{0}\right)$ and the quality of the pollution source is $\mathrm{m}$. Because the radioactive nuclide concentration of the equipment system accident is different with the general radioactive material and the river self degradation ability need not to be considered, it is set that the radioactive nuclide of only can diffuse along the $\mathrm{x}, \mathrm{y}$ and $\mathrm{z}$ direction in this model.

$$
C(x, y, z, 0)=M \delta(x) \delta(y) \delta(z),-\infty<x<\infty,-\infty<y<\infty,-\infty<z<\infty, t>0
$$

$\delta(x)$ is the generalized function that is used to describe the unit concentrated amount and the boundary conditions can be described as follows:

$$
\begin{gathered}
\lim _{x \rightarrow \pm \infty} C(x, y, z, t)=0, \lim _{y \rightarrow \pm \infty} C(x, y, z, t)=0, \lim _{z \rightarrow \pm \infty} C(x, y, z, t)=0 \\
\delta(x)=\left\{\begin{array}{ll}
1, & x=x_{0} \\
0, & x \neq x_{0}
\end{array}, \delta(y)=\left\{\begin{array}{ll}
1, & y=y_{0} \\
0, & y \neq y_{0}
\end{array}, \delta(z)= \begin{cases}1, & z=z_{0} \\
0, & z \neq z_{0}\end{cases} \right.\right.
\end{gathered}
$$

Based on the above conditions, the solution for instantaneous point source pollution three-dimensional diffusion model of equipment system accident radionuclide concentration can be obtained as follows:

$$
C(x, y, z, t)=\frac{M}{8(\pi t)^{\frac{3}{2}} \sqrt{D_{x} D_{y} D_{z}}} \exp \left[-\frac{\left(x-u_{x} t\right)^{2}}{4 D_{x} t}-\frac{\left(y-u_{y} t\right)^{2}}{4 D_{y} t}-\frac{\left(z-u_{z} t\right)^{2}}{4 D_{z} t}-\frac{0.693}{T} t\right]
$$

2) The radionuclide concentration continuous pollution point source three-dimensional diffusion model of equipment system accident:

The solution for continuous point source pollution threedimensional diffusion model of equipment system accident radionuclide concentration can be obtained by the integral type (4) as follows:

$C(x, y, z, t)=\int_{0}^{t} \frac{C_{q} q}{8(\pi t)^{\frac{3}{2}} \sqrt{D_{x} D_{y} D_{z}}} \exp \left[\frac{\left(x-u_{x} t\right)^{2}}{4 D_{x} t}-\frac{\left(y-u_{y} t\right)^{2}}{4 D_{y} t}-\frac{\left(z-u_{z} t\right)^{2}}{4 D_{z} t}-\frac{0.693}{T} t\right] d t(5)$

Among them, $\mathrm{Cq}$ and $\mathrm{q}$ are radioactive pollutant emission concentration and the flow of sewage river respectively.

3) The radionuclide concentration continuous pollution point source three-dimensional steady-state diffusion model of equipment system accident:

The analytical formula for three-dimensional steady-state model is as follows:

$$
C(x, y, z)=\frac{C_{q} q}{4 \pi x \sqrt{D_{y} D_{z}}} \exp \left[\frac{u_{x} y^{2}}{4 D_{y} x}-\frac{u_{x} z^{2}}{4 D_{z} x}-\frac{0.693}{T}\right]
$$

The rapid estimation of the radioactive nuclides transient and continuous pollution spot source diffusion concentration of equipment system radioactive nuclides in liquid and the steadystate calculation of continuous pollution spot source threedimensional diffusion are carried out by using formula (4), (5) and (6).

\section{CASE ANALYSIS}

\section{A. Assumptions}

The simulation conditions of the example can be set as follows: the radioactive pollutants of $20 \mathrm{~kg}$ are thrown into the centre of the river at the initial moment of the accident and the main component is $I^{131}$ which has a half-life of $8.04 \mathrm{~d}$. The related parameters of the river are as follows: the transverse flow velocity of $u_{x}$ in the river is $2 \mathrm{~m} / \mathrm{s}$, longitudinal velocity of $\mathrm{u}_{\mathrm{y}}$ is $0.6 \mathrm{~m} / \mathrm{s}$, the vertical velocity of $\mathrm{u}_{\mathrm{z}}$ is $0.5 \mathrm{~m} / \mathrm{s}$, the transverse diffusion coefficient of $D_{x}$ is $70 \mathrm{~m}^{2} / \mathrm{s}$, the longitudinal diffusion coefficient of $\mathrm{D}_{\mathrm{y}}$ is $15 \mathrm{~m}^{2} / \mathrm{s}$, the vertical diffusion coefficient of $\mathrm{D}_{\mathrm{z}}$ is $5 \mathrm{~m}^{2} / \mathrm{s}$, the average depth of $\mathrm{H}$ is $50 \mathrm{~m}$, and the river flow of $\mathrm{q}$ is $45000 \mathrm{~m} 3 / \mathrm{s}$ and the $\mathrm{Cq}$ is $9.24 \mathrm{mg} / \mathrm{L}$.

\section{B. Simulation Calculation}

Aiming at three-dimensional diffusion simulation model of the instantaneous pollution point source, the MATLAB program is written, and the computer simulation results of instantaneous radioactive pollution point source are shown in figure 1 and figure 2.

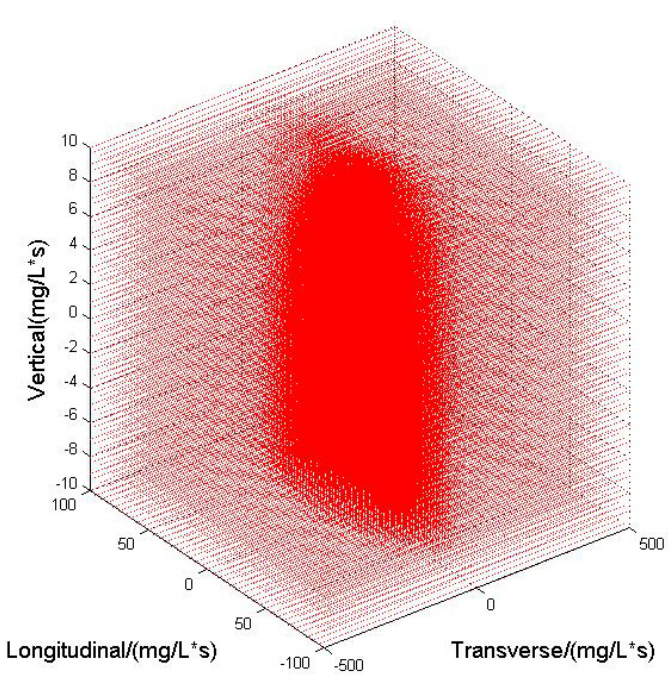

FIGURE I. THE THREE-DIMENSIONAL DIFFUSION GRADIENT VECTOR MAP OF RADIOACTIVE POLLUTION SOURCE AT THE TIME OF 50 SECONDS 


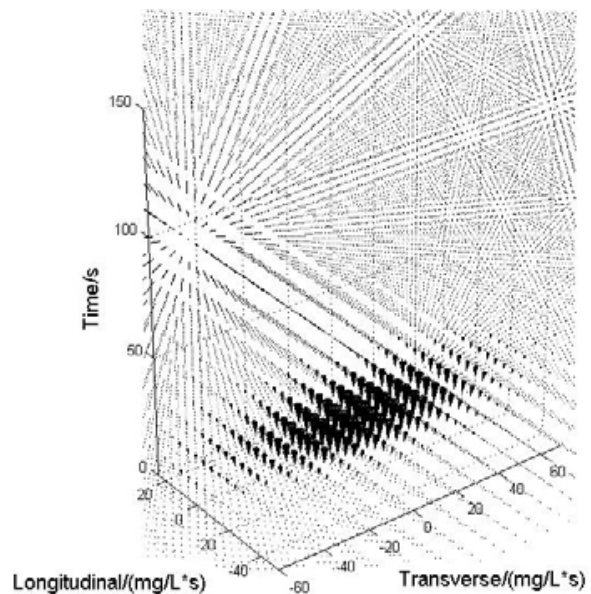

FIGURE II. THE XOY SECTION DIFFUSION GRADIENT FLOW CONE MAP OF RADIOACTIVE POLLUTION SOURCE FROM 10 SECONDS TO 150 SECONDS

The three-dimensional diffusion simulation models of instantaneous radioactive pollution point source and continuous radioactive pollution point source can be considered at the same time, and the matlab program is written to carry out the simulation. The diffusion analysis of instantaneous radioactive pollution point source and continuous radioactive pollution source center and 25 meters under point source at the time of 30 seconds and 300 seconds are simulated, and the simulation results are shown in the following figure 3 and figure 4.

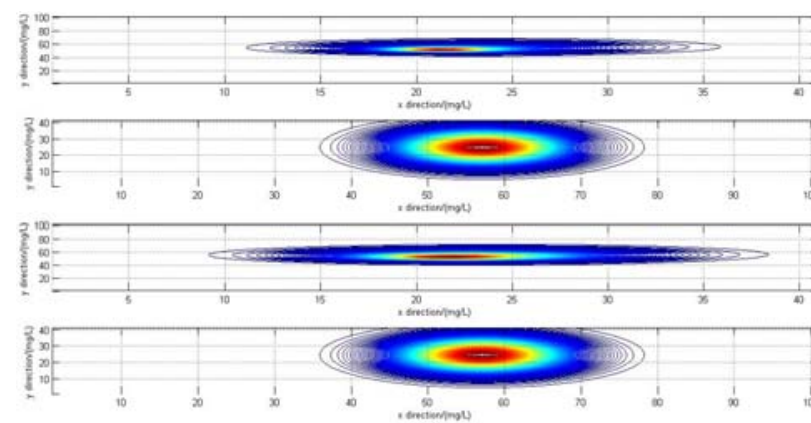

FIGURE III. THE DIFFUSION MAP OF INSTANTANEOUS AND CONTINUOUS RADIOACTIVE POLLUTION POINT SOURCE CENTER AND 25 METERS UNDER POINT SOURCE AT THE TIME OF 30 SECONDS

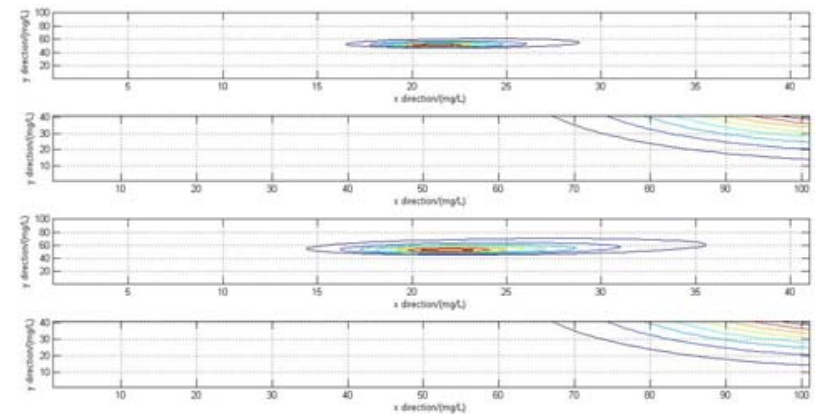

FIGURE IV. THE DIFFUSION MAP OF INSTANTANEOUS AND CONTINUOUS RADIOACTIVE POLLUTION POINT SOURCE CENTER AND 25 METERS UNDER POINT SOURCE AT THE TIME OF 300 SECONDS

\section{CONCLUSION}

The radionuclide concentration diffusion trend of equipment system accident has been simulated by dynamically simulating and analyzing the radionuclide concentration diffusion in water. The research result can play an important role on the scoping of warning zone and acciden reatment area in the emergency rescue process of equipment system accident, and it can provide the scientific basis and theoretical reference for the making of rescue plan and emergency decision.

\section{REFERENCES}

[1] Zhu San-hua, Jin Sheng, Wang Xian-ping. Research on the chloride diffusion model of Pearl River [J]. Modernization, vol.4,pp.1-8,2008.

[2] Jiang Xin-xin, Li Hong. Study on mathematical model of water pollution accident risk prediction $[\mathrm{J}]$. Environmental science and technology, vol.21,pp.6-8,2008.

[3] Zhang Ji-hua, Wang Xin-yuan, Tian Bing. The visualization study on the river one-dimensional diffusion model $[\mathrm{J}]$. Computer technology and development, vol.18,pp.240-242,2008. 